\title{
Nasal Congestion
}

National Cancer Institute

\section{Source}

National Cancer Institute. Nasal Congestion. NCI Thesaurus. Code C78500.

The blockage of the nasal passage due to mucosal edema. It is usually the result of a viral infection or an allergic reaction. 